\title{
NEUROPEPTIDES
}

\section{Hemodynamic Effects of Endothelin after Systemic and Central Nervous System Administration in the Conscious Rat}

\author{
A-L. SIRÉN and G. FEUERSTEIN* \\ Department of Neurology, Uniformed Services University of the Health Sciences 4301 Jones Bridge \\ Road, Bethesda, Maryland 20814, USA. *Department of Pharmacology, Smith Kline and Beckman \\ Research and Development, 709 Swedeland Road, King of Prussia, Pennyslvania 19406, USA (reprint \\ requests to A-LS)
}

\begin{abstract}
The effects of endothelin-1 (ET-1) administered i.v. or intracerebroventricularly (i.c.v.) on arterial pressure (MAP), heart rate and cardiac output were studied in the conscious rat. Systemic injection of ET-1 $(0.1$ to $1 \mathrm{nmol} / \mathrm{kg}$ i.v.) increased dose-dependently MAP and decreased heart rate. The doses of 0.3 and $1 \mathrm{nmol} / \mathrm{kg}$ produced initially transient hypotension and tachycardia which were accompanied by a decrease in total peripheral resistance index (TPRI). Cardiac output was significantly reduced and TPRI increased during the pressor response to 0.3 and $1 \mathrm{nmol} / \mathrm{kg} \mathrm{ET-1.} \mathrm{ET-1} \mathrm{i.c.v.} \mathrm{(} 30 \mathrm{pmol} / \mathrm{kg}$ ) produced a profound pressor and vasoconstrictor response which was followed by cardiovascular collapse and death within 20 min after i.c.v. injection. Low doses (1 to $10 \mathrm{pmol} / \mathrm{kg}$ ) of ET-1 i.c.v. had no effect on the cardiovascular system.

The present data are in accordance with the studies demonstrating biphasic blood pressure and heart rate responses to i.v. ET-1 in the rat. Profound cardiac depressor and peripheral vasoconstrictor responses were found to accompany the pressor phase. Our results also showed for the first time direct central pressor and vasoconstrictor effects of ET-1 insinuating that endothelin might be a neuropeptide participating in the central cardiovascular control.
\end{abstract}

\section{Introduction}

Endothelin is an endothelium-derived 21-residue peptide which has powerful vasoconstrictor potency on a variety of isolated blood vessels and upon intravenous administration in intact animals produces dose-dependent pressor and vasocon-

Date received 25 May 1989

Date accepted 30 May 1989 strictor effects which are preceded by a transient hypotensive and vasodilator response $(1,2,3,4$, 5 ). In the rat the initial hypotensive response to endothelin was accompanied by carotid and hindquarter skeletal muscle vasodilation and renosplanchnic vasoconstriction which were followed by increases in blood pressure due to strong generalized constriction of all vascular beds (5). However, these experiments were conducted in 
the anesthetized paralyzed rat, a preparation which might not reveal the full scope of hemodynamic responses to endothelin in the conscious state. In the conscious rat, i.v. administration of endothelin was recently reported to produce predominantly vasoconstrictor responses in mesenteric and hindquarter blood vessels (6).

The human endothelin was shown to exist in three isoforms; ET-1 identical to the classical endothelin isolated originally from porcine and human aorta, endothelin-2 identical to the peptide originally derived from human endothelial cells and endothelin-3 identical to endothelin isolated first from rat endothelial cells (2). The three isoforms of endothelin exhibited distinct profile of cardiovascular activity in anesthetized rats; ET-1 being most potent vasoconstrictor both in vivo and in vitro while endothelin-3 displayed most profound initial hypotensive response (2). Tissue autoradiographic studies in rats have demonstrated that specific high-affinity binding sites for ET-1 are distributed not only in vascular and cardiac muscle but are abundantly present in the central nervous system $(7,8,9)$. Therefore, the present study was set to examine the effects of endothelin on systemic hemodynamic variables as well as on blood pressure and cardiac functions in conscious rats after intravenous and intracerebroventricular (i.c.v.) administration.

\section{Materials and Methods}

Male Sprague-Dawley rats $(300-360 \mathrm{~g})$ were purchased from Taconic Farms (Germantown, N.Y.) and housed at $22^{\circ} \mathrm{C}$ with a $12 \mathrm{~h} / 12 \mathrm{~h}$ light/dark cycle. After surgical operations the rats were housed individually in plastic cages $(21 \times 27 \times$ $16 \mathrm{~cm}, \mathrm{~W} \times \mathrm{L} \times \mathrm{H}$ ) with food and water ad libitum.

\section{Measurement of cardiac output}

The cardiac output was measured by thermodilution technique as previously described in detail $(10,11)$. The principle of this technique is to produce a change in heat content of blood at one point of the circulation (right atrium) and detect the resultant change in temperature at a point downstream (ascending aorta). Although the cardiac output values obtained by thermodilution tend to be somewhat higher than those determined by electromagnetic flowmetry $(12,13)$ or by radioactive microsphere method (14), the thermodilution method offers many advantages, including (a) the possibility to do repeated cardiac output recordings in a conscious chronically instrumented rat and, (b) in contrast to Doppler velocimetry (15) or electromagnetic flowmetry (12), thermodilution does not require the extensive open chest surgery with high mortality and prolonged postoperative recovery.

Each rat to undergo cardiac output measurements was anesthetized with an intramuscular injection of ketamine $(130 \mathrm{mg} / \mathrm{kg})$ and acepromazine $(1.3 \mathrm{mg} / \mathrm{kg})$ and a PE-50 catheter was inserted into the left femoral artery. The catheters were tunneled under the skin and exited at the nape of the neck. An incision was made at the midline of the neck from the cricoid to the clavicle, and a PE-50 catheter was inserted into the right atrium via the external jugular vein. The left common carotid artery was exposed and ligated, and a thermistor (MX2-780-33 model THMP f 1.5, Teflon reusable, Columbus Instruments, $\mathrm{OH}$ ) was advanced through the carotid into the ascending aorta. Placement above the aortic valve was confirmed in each animal by the shape of the dilution curve before the probe was finally sutured to the neck muscles and again at the end of experiment. The jugular vein catheter and the thermistor leads were tunneled under the skin to the nape of the neck. All catheters and the probe wire were secured by a soft spring wire attached to the animals's neck using an adhesive collar. Twentyfour hours after the surgery, the arterial line was connected to a pressure transducer (Narco BioSystems model RP 1500i] attached to a strain gauge coupler (Narco Bio-Systems type 7032). Blood pressure (mean, systolic, diastolic, pulse) and heart rate were continuously recorded on a Narcotrace 80 computerized physiograph and sampled automatically at $30-60$ s intervals by a Northstar-Hazeltine computer.

To obtain measurements of cardiac output, the aortic thermistor was attached to the computerized Cardiomax II (CMX-780-k with microprobe option $\mathrm{R}$, Columbus Instruments, $\mathrm{OH}$ ). The dead space of the venous line was first flushed with $50 \mu \mathrm{l}$

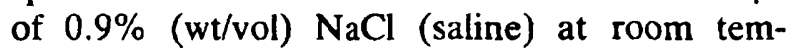


perature $\left(22^{\circ} \mathrm{C}\right)$; after a brief stabilization period an additional injection of $200 \mu \mathrm{l}$ normal saline $\left(22^{\circ} \mathrm{C}\right)$ was rapidly injected into the right atrium using a $1 \mathrm{ml}$ syringe, and the blood temperature monitored by the aortic thermistor. The thermodilution curve representing the change in aortic temperature was then calculated by the Cardiomax II. A control period of $15 \mathrm{~min}$ included two or three cardiac output recordings to test for consistency and placement of the probe. During this time period, control values for blood pressure and heart rate also were collected. The timer for automatic data collection was started and data points for blood pressure, heart rate and cardiac output were collected immediately before and 1, 2.5, 5, 20, 30 and $60 \mathrm{~min}$ after drug injections. Total peripheral resistance (TPR) was calculated by dividing the mean arterial pressure by the cardiac output; values of cardiac output and TPR were further indexed per unit of weight $(\mathrm{kg})$. Core temperature was monitored by the aortic thermoprobe before each cardiac output measurement.

\section{Intracerebroventricular injections}

Rats were anesthetized with ketamine-acepromazine (see above) and placed on a stereotaxic device (David Kopf Instruments, Calif.). A stainless steel guide cannula was inserted through the skull and fixed with glue (Eastman 910 Adhesive). Coordinates for the injections into the right lateral brain ventricle (i.c.v.) were measured from the bregma: $\mathrm{AP}=-0.8 \mathrm{~mm}$ and $\mathrm{L}=1.2 \mathrm{~mm}$. On the day of the experiment, injections of saline or endothelin were made using a premeasured $30-\mathrm{g}$ $(7.5 \mathrm{~mm})$ cannula inserted into the ventricular space through the guide cannula. The injection cannula was then connected via polyethylene tubing to a Hamilton microliter syringe, and a volume of $10 \mu$ l of the control or drug solution was injected over a period of 30 seconds. The proper position of the i.c.v. cannula was determined at the end of each experiment by an injection of dye (methylene blue) into the cerebral ventricles.

\section{Statistical analysis of the data}

Data in text and figures are means $\pm S$.E. for the given number of rats. Analysis of variance with repeated measures (general MANOVA) and
ANOVA with Student-Newman-Keul's test (CSS Complete Statistical System, StatSoft, 1987) were used for statistical analysis of the data.

\section{Drugs used}

Endothelin-1 (ET-1, porcine endothelin) was purchased from Peptides International. The stock solution was dissolved in physiological saline $(0.9 \%)$ and stored aliquoted in $-20^{\circ} \mathrm{C}$. The dilutions were prepared fresh each day.

\section{Results}

A. Hemodynamic effects of intravenously administered endothelin

The effects of increasing doses of ET-1 i.v. on hemodynamic variables are summarized in Figure 1. Intravenous injection of ET-1 at the doses of $0.1-1 \mathrm{nmol} / \mathrm{kg}$ increased dose-dependently mean arterial pressure. The two highest doses 0.3 and $1 \mathrm{nmol} / \mathrm{kg}$ ) initially decreased blood pressure. The pressor responses to ET-1 were accompanied by bradycardia and the initial depressor phase by a tachycardic response. The maximum increase in blood pressure became apparent 2-5 min after the injection of the lower doses of ET- 1 and these responses subsided within $20 \mathrm{~min}$. After the highest dose the maximum pressor effect was reached in $10 \mathrm{~min}$ and the blood pressure remained significantly elevated over the whole observation period of $60 \mathrm{~min}$.

Cardiac index was significantly decreased after 0.3 and $1 \mathrm{nmol} / \mathrm{kg}$ doses of ET-1. The decrease in cardiac index after the $1 \mathrm{nmol} / \mathrm{kg}$ dose reached its maximum 5 min after ET-1 injection and the cardiac index remained reduced over $60 \mathrm{~min}$. The doses of 0.3 and $1 \mathrm{nmol} / \mathrm{kg}$ of ET- 1 initially decreased total peripheral resistance. The decrease in total peripheral resistance was followed by a sustained vasoconstriction and increase in peripheral resistance.

\section{B. Hemodynamic effects of centrally admin- istered endothelin}

The hemodynamic responses to i.c.v. administration of ET-1 at doses of $1,3,10$ and $30 \mathrm{pmol} / \mathrm{kg}$ are summarized in Figure 2. ET-1 i.c.v. at doses up to 


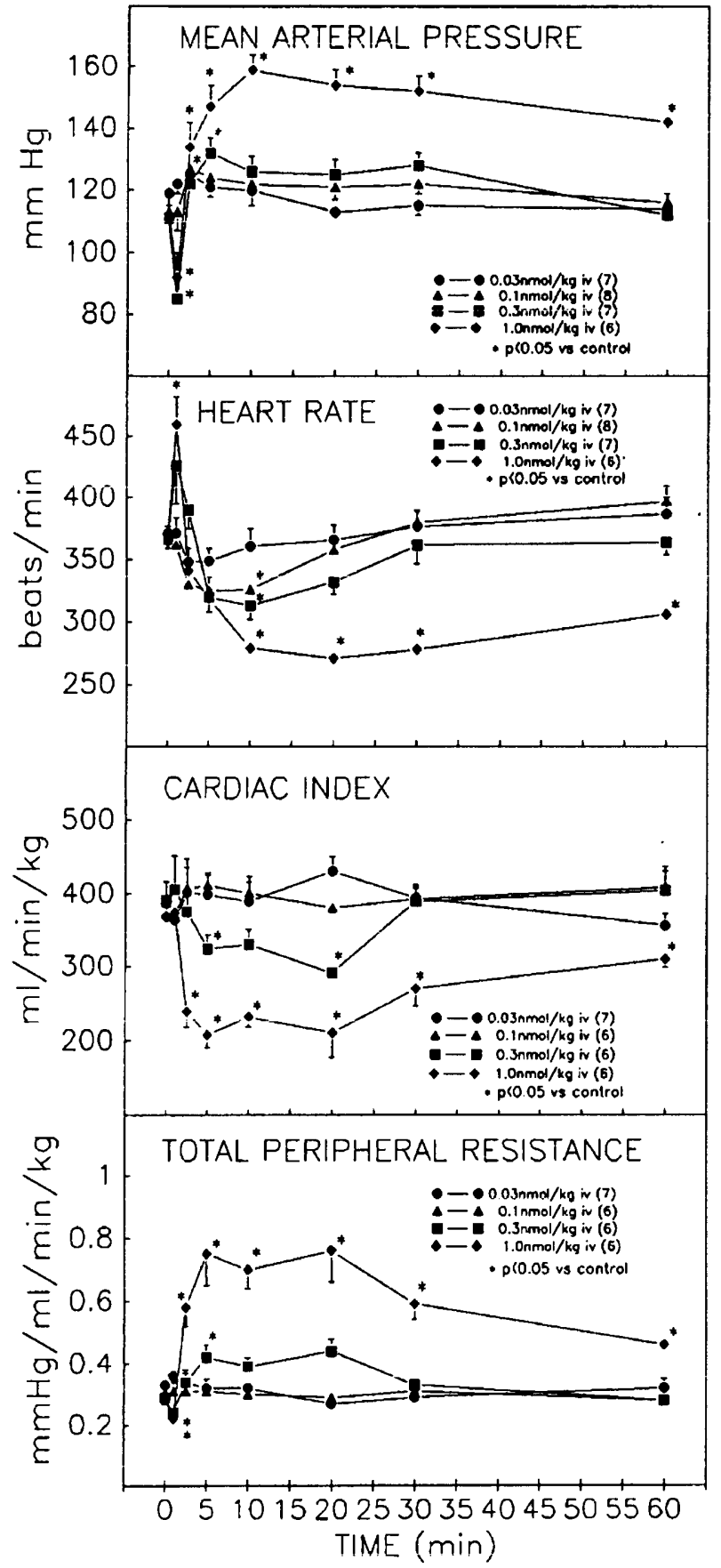

Fig. 1 Hemodynamic effects of intravenously administered ET-1 in the conscious rat. Increasing doses of ET-1 (0.03$1 \mathrm{nmol} / \mathrm{kg}$ ) were injected i.v. at $60 \mathrm{~min}$ intervals. Values indicate mean $\pm S E M$. The number of animals in each group is indicated in parenthesis. Asterisks indicate statistical significance from baseline by Student-Newman Keul's test.

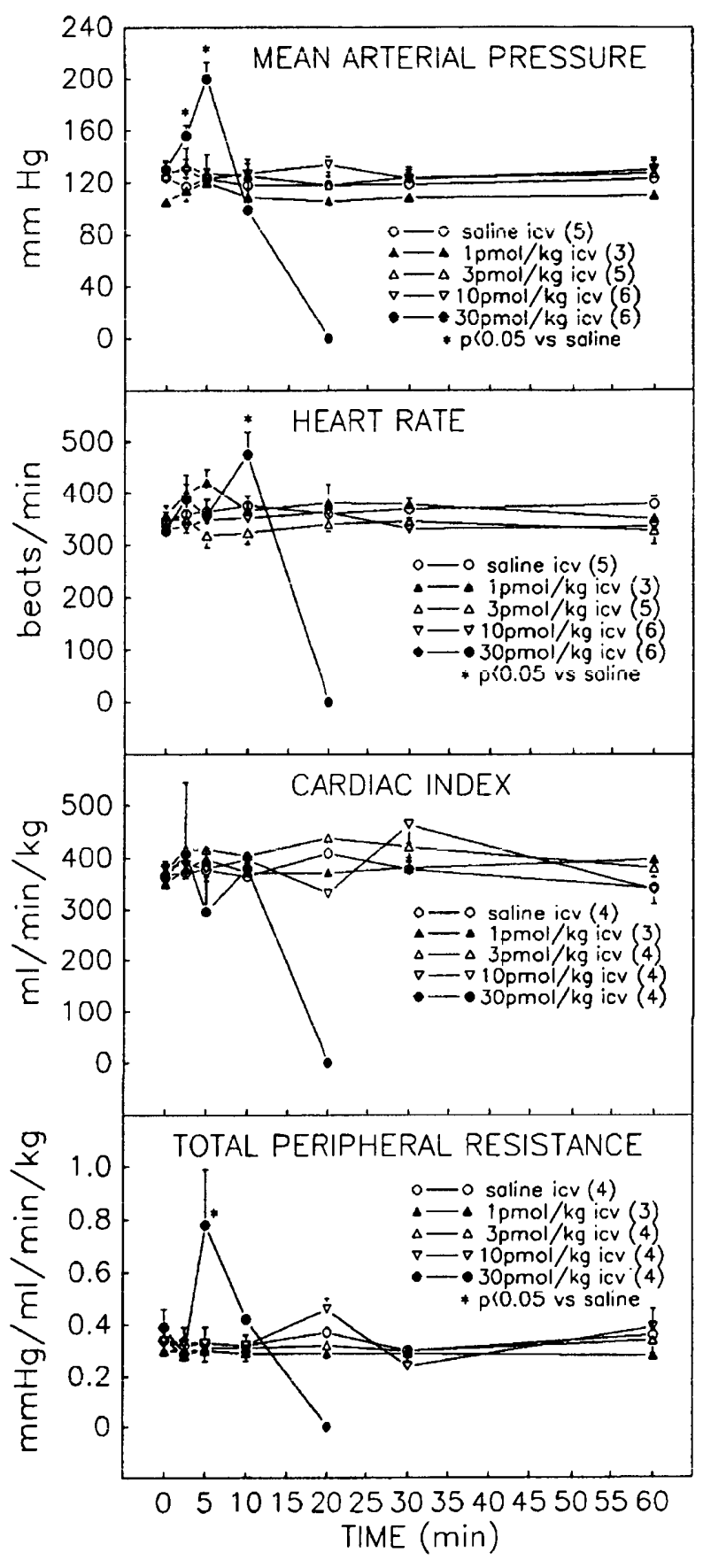

Fig. 2 Hemodynamic effects of intracerebroventricularly (i.c.v.) administered ET-1 in the conscious rat. Saline $(10 \mu \mathrm{l})$ or increasing doses of ET-1 (1-30 pmol/ $\mathrm{kg})$ were injected i.c.v. at 60 min intervals. Values indicate mean \pm SEM. The number of animais in eacl group is indicated in parenthesis. Asterisks indicate statistical significance from saline by Student-Newman Keul's test. 
$10 \mathrm{pmol} / \mathrm{kg}$ had no effect on cardiovascular variables, whereas the $30 \mathrm{pmol} / \mathrm{kg}$ produced a profound pressor response and increase in total peripheral resistance. The mean arterial pressure increased from $123 \pm 3 \mathrm{mmHg}$ baseline to $200 \pm$ $5 \mathrm{mmHg}$ within $5 \mathrm{~min}$ after the i.c.v. injection. Heart rate increased $(+149 \pm 34 \mathrm{bpm}, \mathrm{p}<0.01$ vs. saline) $15 \mathrm{~min}$ after injection. The pressor and tachycardic responses were followed by cardiovascular collapse and death (in 7 out of 8 animals) $20 \mathrm{~min}$ after the i.c.v. injection of ET-1. The cardiovascular response to the $30 \mathrm{pmol} / \mathrm{kg}$ dose of ET-1 i.c.v. was accompanied by barrel rolling behaviour within seconds after the i.c.v. injection and at the terminal phase grand mal-type convulsions.

\section{Discussion}

Our results are in accordance with recent reports demonstrating pressor responses to intravenous endothelin in the rat $(1,2,3,4,5)$. The present study provides a clear mechanism for the increase in systemic blood pressure; peripheral vasoconstriction and elevated TPR. In fact the relatively moderate response to ET-1 could be the result of the counteracting effect of decreased cardiac output by ET-1. Our results are supported by studies showing construction of vascular smooth muscle by endothelin in various in vitro preparations (1, $16,17)$ and increase regional vascular resistance in vivo in the renal>mesenteric $>$ hindquarter blood vessels after systemic administration of endothelin in intact rats $(6,18)$.

Several factors could have contributed to the decreased in cardiac index: Heart rate was reduced concomitantly with the decreased cardiac index and a reflex bradycardia due to the increase in systemic pressure could thus confer to the fall in cardiac output. An increased afterload due to elevated peripheral resistance as well as decreased preload due to peripheral vasoconstruction could also contribute to the reduced cardiac output. A direct negative inotropic effect seems unlikely since endothelin was recently shown to increase tension in the isolated rat atrial and papillary muscle (19). However, reduction in myocardial contractility could be secondary to coronary vasoconstriction (20).
At the high doses of ET-1 i.v. the pressor and cardiac depressant effects were preceded by hypotensive and vasodilator responses. An initial hypotensive response preceding the pressor phase of endothelins has been reported after systemic administration of endothelin in a variety of species including the rat $(1,2,3,4,5,6)$. In the anesthetized cat the depressor response was associated with tachycardia, an increase in cardiac output and reduction of total peripheral resistance (3). In our study the cardiac output remained unchanged during the hypotension while the total peripheral resistance decreased. Species differences may explain this discrepancy in response to endothelin in the rat vs cat. It might also be possible that due to the transient nature of the positive inotropic response the increase in cardiac index was not detected by the thermodilution technique since this method does not allow repetitive measurements within a short (less than $60 \mathrm{sec}$ ) time frame. However, our study clearly indicates that vasodilation leading to decreased peripheral vascular resistance underlies the hypotensive response to ET-1.

Our study reports for the first time profound hypertensive and tachycardic response and $90 \%$ mortality due to cardiovascular collapse after intracerebroventricular application of a picomole dose of ET-1 in the conscious rat. The extremely high potency of i.c.v. administered ET-1 implies that this peptide may be a neuromodulator important for the central cardiovascular regulation. Surprisingly, in our study no clear dose-response relationship of the central effects of ET-1 was established. This might indicate an extremely steep dose-response relationship to ET-1, but alternatively an unspecific toxic effect unrelated to a specific receptor cannot be excluded. However, the presence of specific binding sites for endothelin in many brain regions including the hypothalamic and brain stem cardiovascular nuclei $(7,8,9)$ supports the possibility that endothelin might be a neurotransmitter.

In summary the present data demonstrate that profound cardiac depressor and peripheral vasoconstrictor responses underlie the previously described changes in blood pressure by ET-1. Our results also show that ET-1 is a most potent central modulator of the cardiovascular system at doses 
well below any known peptide, amine, amino acid or other known neurotransmitter or neuromodulator. Therefore we suggest that endothelin might be a neuropeptide in the central cardiovascular control.

\section{Acknowledgements}

This work was supported by the United States Army Medical Research and Development Command Protocol \#G39228. The opinions or assertions contained herein are the private ones of the authors and are not to be construed as official or as necessarily reflecting the views of the Department of Defense or the Uniformed Services University of the Health Sciences. The experiments reported herein were conducted according to the principles set forth in the Guide for Care and Use of Laboratory Animals, Institute of Laboratory Animal Resources, National Research Council (DHEW Publication No. NIH 78-23, 1978).

\section{References}

1. Yanagisawa, M., Kurihara, H., Kimura, S., Tomobe, Y., Kobayashi, M., Mitsui, Y., Yazaki, Y., Goto, K. and Masaki, T. (1988). A novel potent vasoconstrictor peptide produced by vascular endothelial cells. Nature 332: 441 415.

2. Inoue, A., Yanagisawa, M., Kimura, S., Kasuya, Y., Miyauchi, T., Goto, K. and Masaki, T. (1989). The human endothelin family: Three structurally and pharmacologically distinct isopeptides predicted by three separate genes. Proc. Natl. Acad. Sci. USA 86: 2863-2867.

3. Lippton, H., Goff, J. and Hyman, A. (1988). Effects of endothelin in the systemic and renal vascular beds in vivo. Eur. J. Pharmacol. 155: 197-199.

4. Lippton, H. L., Hauth, T. A., Summer, W. R. and Hyman, A. L. (1989). Endothelin produces pulmonary vasoconstriction and systemic vasodilation. J. Appl. Physiol. 66: 1008-1012.

5. Wright, C. E. and Fozard, J. R. (1988). Regional vasodilation is a prominent feature of the haemodynamic response to endothelin in anesthetized, spontaneously hypertensive rats. Eur. J. Pharmacol. 155: 201-203.

6. Han, S. P., Trapani, A. J., Fok, K. F., Westfall, T. C. and Knuepfer, M. M. (1989). Effects of endothelin on regional hemodyamics in conscious rats. Eur. J. Pharmacol. 159: 303-305.
7. Koseki, V., Imai, M., Hirata, Y., Yanagisawa, M. and Masaki, T. (1989). Autoradiographic distribution in rat tissues of binding sites for endothelin: a neuropeptide? Am. J. Physiol. 256: R858-R866.

8. Ambar, I., Kloog, Y., Schwartz, I., Hazum, E. and Sokolovsky. M. (1989). Competitive interaction between endothelin and sarafotoxon: Binding and phosphoinositides hydrolysis in rat atria and brain. Biochem. Biophys. Res. Commun. 158: 195-201.

9. Jones, C. R., Hiley, C. R., Pelton, J. T. and Mohr, M. (1989). Autoradiographic visualization of the binding sites for [ ${ }^{125}$ I] endothelin in rat and human brain. Neurosci. Lett. 97: 276-279.

10. Sirén, A.-L., Lake, C. R. and Feuerstein, G. (1988) Hemodynamic and neural mechanisms of action of thyrotropin releasing hormone in the rat. Circ. Res. 62:139-154.

11. Sirén, A.-L. and Feuerstein, G. (1988). Cardiovascular effects of rat calcitonin gene-reiated peptide in the conscious rat. J. Pharm. Exp. Ther. 247: 69-78.

12. Lappe, R. W., Smits, J. F. M., Todt, J. A., Debets, J. J. M. and Wendt, R. L. (1985). Failure of atriopeptin II to cause arterial vasodilation in the conscious rat. Circ. Res. 56: 606-612.

13. Osborn, J. W., Barber, B. J., Quillen, E. W., Abram, R. J and Cowley, A. W. (1986). Chronic measurement of cardiac output in unanesthetized rats using miniature thermocouplers. Am. J. Physiol. 251: H1365-H1372.

14. Ishise, S., Pegram, B. L., Yamamoto, J., Kitamura, Y. and Frölich, E. D. (1980). Reference sample microsphere method: Cardiac output and blood flows in conscious rat. Am. J. Physiol. 239. H443-H449.

15. Werber, A. H., Bryan, W. J. and Fink, G. D. (1984). Hemodynamic and neural mechanisms of acute neurogenic hypertension in the rat. Am. J. Physiol. 247: H991-H998.

16. Tabuchi, Y., Nakamuru, M., Rakugi, H., Nagano, M. and Ogihara, T. (1989). Endothelin enhances adrenergic vasoconstriction in perfused rat mesenteric arteries. Biochem. Biophys. Res. Commun. 159: 1304-1308.

17. Warner, T. D., de Nucci, G. and Vane, J. R. (1989). Rat endothelin is a vasodilator in the isolated perfused mesentery of the rat. Eur. J. Pharmacol. 159: 325-326.

18. Rohmeiss, P., Photiadis, J., Rohmeiss, S. and Unger, Th. (1989). Hemodynamic characterization of endothelin in conscious rats. Am. J. Hypertens 2: 115A

19. Schomisch-Moravec, C., Reynolds, E. E., Stewart, R. W. and Bond, M. (1989). Endothelin is a positive inotropic agent in human and rat heart in vitro. Biochem. Biophys. Res. Commun. 159: 14-18.

20. Ezra, D., Goldstein, R. E., Czaja, J. F. and Feuerstein, G $Z$. (1989). Lethal ischemia due to intracoronary endothelin in the pig. Am. J. Physiol., in press. 